\title{
Three-dimensional Computed Tomography Scan Whiskering in Ankylosing Spondylitis: A View from Inside
}

ISMAEL CALERO-PANIAGUA, PhD; CARLOS MONTILLA, PhD, MD; TATIANA CARRANCO-MEDINA, PhD; MARÍA DOLORES SÁNCHEZ-GONZÁLEZ, PhD; ALBA QUESADA-MORENO, PhD, Hospital Clinico Universitario Salamanca, Rheumatology; RICARDO USATEGUI-MARTÍN, Universidad de Salamanca, Molecular Medicine Unit; SUSANA GÓMEZ, PhD, MD; CRISTINA HIDALGO-CALLEJA, PhD; JAVIER DEL PINO-MONTES, PhD, MD, Hospital Clinico Universitario de Salamanca, Rheumatology, Salamanca, Spain. Address correspondence to I. Calero-Paniagua, Hospital Universitario de Salamanca, Rheumatology Service, Paseo de San Vicente 58, 37007, Salamanca, Spain. E-mail: ismaelcaleropaniagua@yahoo.es. J Rheumatol 2014;41:1428-9; doi:10.3899/jrheum.131257

Ankylosing spondylitis (AS) is the prototype of diseases that belong to the category of spondyloarthropathies. AS usually affects the sacroiliac joints and invariably involves the axial skeleton. Peripheral joint involvement, enthesitis, and extraskeletal manifestations are also important clinical and radiographic features of the disease ${ }^{1,2}$.

A 55-year-old man was diagnosed with AS at the age of 18 years. He initially presented with both axial and peripheral involvement, including heel enthesitis and acute anterior uveitis. He had been doing well with nonsteroidal antiinflammatory drugs and sulfasalazine. At his most recent regular examination, he had experienced moderate pain at the proximal and lateral aspects of both thighs for several weeks. Clinical examination revealed signs of spinal ankylosis and tenderness over the trochanters.

The patient was injected into the left greater trochanter twice, but without clinical improvement. Radiographs (Figure 1) showed sacroiliac fusion, whiskering at both ischial tuberosities, degenerative changes of both hips, and an uncertain lytic image at the right trochanter (possibly due to overpenetration of the radiograph). A computerized tomography (CT) scan was subsequently obtained, which revealed irregularity of the right trochanter, representing a possible avulsion of the tendinous insertion, osteoarthritic changes in both hips, and exuberant enthesopathy and bone proliferation at the ischial tuberosities. A 3-D volume rendering of the CT was performed (Figures 2 and 3), highlighting these findings. Eventually the patient was referred to the rehabilitation service and is doing well with ultrasound and laser therapy.

The 3-D volume renderings from the CT scan show how dramatic enthesitis can be in these patients.

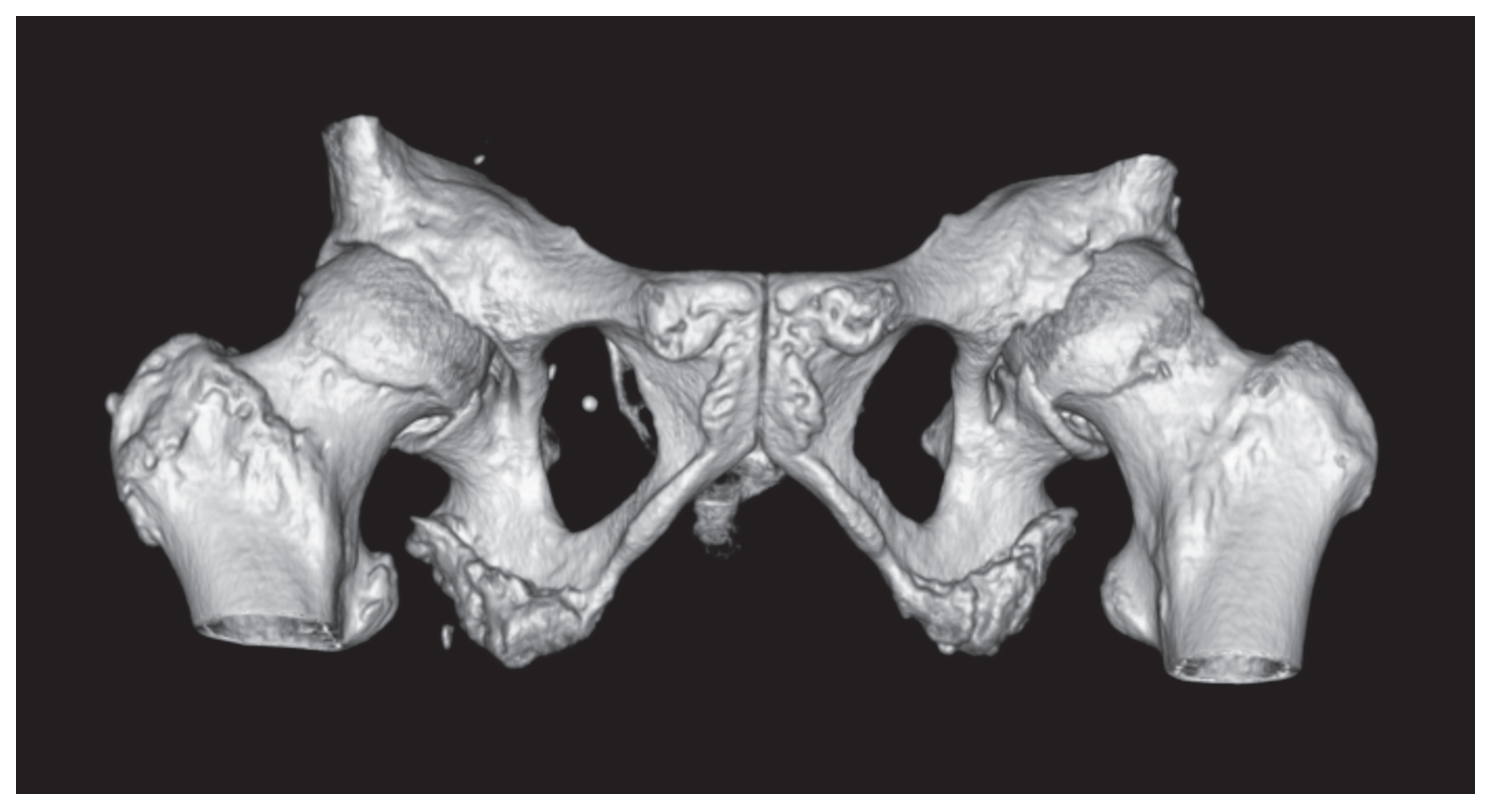

Figure 1. Anteroposterior view of whiskering.

Personal non-commercial use only. The Journal of Rheumatology Copyright (C) 2014. All rights reserved. 




Figure 2. Posteroanterior view of whiskering.

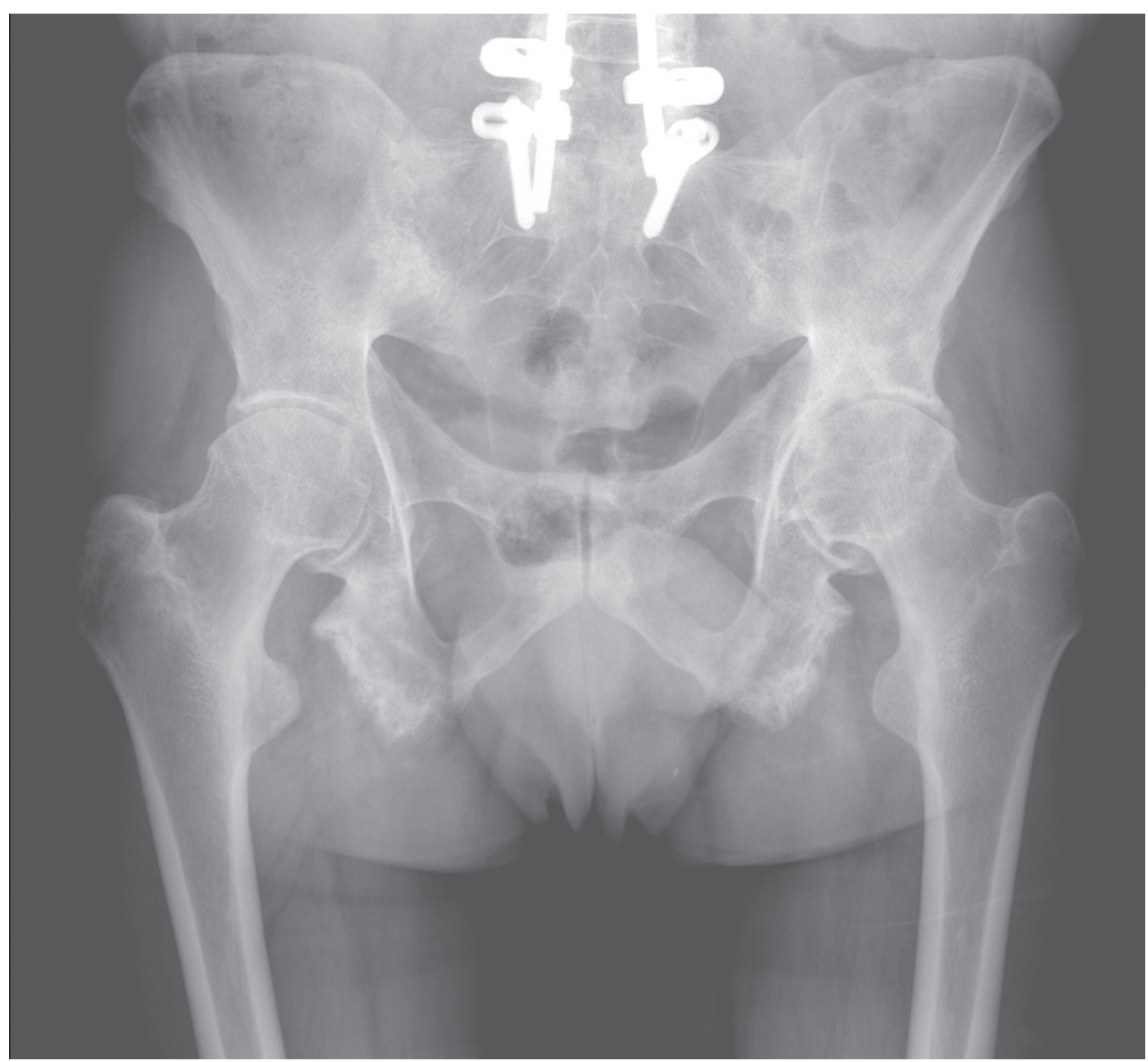

Figure 3. Radiograph showing whiskering.

\section{REFERENCES}

1. Braun J, van der Heijde D. Spondylarthropathies. Best Pract Res Clin Rheumatol 2006;20:399-400.
2. van Tubergen A, Weber U. Diagnosis and classification in spondyloarthritis: identifying a chameleon. Nat Rev Rheumatol 2012;8:253-61. 